\title{
Forecasting of Sudan Airways Domestic Services Total Cost
}

\author{
Maysoon A. Sultan ${ }^{* 1}$, Mohammed H. Mudawi ${ }^{2}$ and Afra H. Abdellatif ${ }^{3}$ \\ ${ }^{* I}$ Department of Statistics, Faculty of Science, Sudan University for Sciences and Technology, Khartoum, \\ Sudan. \\ ${ }^{2}$ Department of Statistics, Faculty of Science, Juba University, Juba, South Sudan. \\ ${ }^{3}$ Department of Statistics, Faculty of Science, Sudan University for Sciences and Technology, Khartoum, Sudan.
}

\begin{abstract}
This paper attempt to estimate and forecast the total cost of Sudan Airways domestic services. The data were obtained from the Planning Directorate of Sudan Civil Aviation Authority, Air Transport Directorate and Sudan Airways Directorate of Central Planning. The data were statistically analyzed the annual cost function of Sudan Airways for the period from 2004 to 2013. The researcher study was to find out how the total cost (TC) behaves in relation to the domestic output, in revenue passenger (PAX), cargo/freight (FRT), fuel cost $(F C)$ and load factor $(L F)$. The result shall lead us to estimate an airline cost function, by using Classical Normal Regression model (CNLRM) to analyze the data obtained for this research. The model is represented as follows:

$T C_{t}=\beta_{0}+\beta_{1} P A X_{t}+\beta_{2} F R T_{t}+\beta_{3} L F_{t}+\beta_{4} F C_{t}+u_{t}$

$t=1,2, \ldots, 10$

The Classical Normal Linear Regression Model (CNLRM) is acceptable to the predictive purpose of forecasting the function of Sudan Airways total cost, with a high statistically significant value at $5 \%$ level. This result means that the estimated regression models make sense; with strong power for prediction and forecast. From the forecast result for the period 2014-2018 the researcher concluded that the total cost of Sudan Airways, shall gradually decrease during the next five years. This is clearly noted in Sudan Airways activities as reflected in their current actual status in 2016, due to the decreasing number of their fleet that minimizes their activities.
\end{abstract}

Keywords: Classical Linear Regression Model, Passenger, Freight, Fuel Price, Load Factor.

\section{Introduction}

Sudan Airways is a national airline in Sudan, headquartered in Khartoum since 1946 .The carrier is a member of the International Air Transport Association (IATA), of the Arab Air Carriers Organization since 1965, and of the African Airlines Association since 1968, becoming a founding member along with ten companies. In 2007, the Sudanese government privatized the airline \& sold it to a Kuwaiti private group for four years. The Airline has been included in the list of airlines banned in the European Union since March, 2010. As of December 2011, the company is reowned by the Government of Sudan, and has 1,700 employees. As of July 2011, the airline serves twenty four destinations in Africa , ten of them within Sudan and the Middle East.

Sudan Airways fleet consisted of the following aircraft, with an average age of seventeen years:

Table (1): Sudan Airways Fleet (Seventeen Years Ago):

\begin{tabular}{|r|r|}
\hline Aircraft & In Fleet \\
\hline Airbus A300B4 /-600R & 2 \\
\hline Airbus A320-200 & 2 \\
\hline Boeing 737-500 & 1 \\
\hline Fokker 50 & 3 \\
\hline Yakovlev Yak-42D & 1 \\
\hline Total & $\mathbf{9}$ \\
\hline
\end{tabular}

Source: S.A.C. Planning Directorate (2012).

Sorrowfully, Sudan Airways currently operates only one aircraft due to its privatization and selling 70\% of its shares in 2007 to a non-aviation- minded foreign Arab businessman, who had paralyzed this famous first aviation pioneer international Airline in Africa and all Arab countries and the Middle East. Due to his absolute failure to run the Airline, he had to sell its stake back to Sudan in 2011.

As of June, 2014, Sudan Airways active fleet consists of the following aircraft: 
Table (2): Sudan Airways Active Fleet:

\begin{tabular}{|l|l|}
\hline Aircraft & In Fleet \\
\hline Airbus A300B4-600R & 2 \\
\hline Airbus A320-200 & 2 \\
\hline Fokker 50 & 3 \\
\hline Total & $\mathbf{7}$ \\
\hline
\end{tabular}

Source: S.A.C. Planning Directorate.

The company has flown more than thirty equipment of various types through its long history. Sudan Airways' operations have generally shown losses, and in the early 1980s the corporation was reportedly receiving an annual government subsidy of about 500,000 Sudanese ponds. In 1987 the government proposed to privatize Sudan Airways, precipitating a heated controversy that ultimately led to a joint venture between the government and private interests. Like the railroads and river transport operators, however, Sudan Airways suffered from a shortage of skilled personnel, overstaffing, and lacked hard currency and credit for spare parts and proper maintenance. ${ }^{(3)}$ During the last forty years the airline experienced 21 accidents/incidents, 7 of which lead to fatalities ... The worst accident was in July, 2003 near Port Sudan, when 117 were killed.

In this paper ten years annual data of total domestic passengers and cargo, from 2004 to 2013, are statistically analyzed to determine a cost function.

\section{Research Problem:}

Preface:

1. Covers all States of Sudan.

2. Sudan Airways Domestic movements carrying passengers and cargo during 2004- 2013.

The research objectives are list below:

1. Evaluation of Sudan Airways domestic Services in Sudan in regards to Passenger / Cargo Movements.

2. Statistical Estimation \& Forecast of a Sudan Airways cost function to identify the extent of aviation development in Sudan.

\section{Materials \& Methods}

Cost models are mathematical representation of the relationship between the total cost and explanatory variables (the output, in revenue passenger and cargo, fuel price and load factor), model specification reflects expectations of cost behavior, by using the Classical Normal Linear Regression Model (CNLRM), to evaluate the model for forecasting, by satisfying the main features of a good regression model.

\section{Theoretical Frame:}

Analysis of the data obtained from the Planning Directorate of Sudan Civil Aviation Authority, Air Transport Directorate and Sudan Airways Directorate of Central Planning. These data consist of the total number of passengers and freight/cargo carried domestically in Sudan Airways, and also the data consist of the total number and types of aircraft in Sudan Airways through the years from 2004 to 2013. Addition of that the data of Fuel price obtained from Nile Bakri Aviation Co.Ltd., and price of currency from Bank of Sudan; which were used in calculation of Sudan Airways total cost.

\section{Specifications and Estimation of the Models:}

- The data analyze the annually cost of Sudan Airways for the period from 2004 to 2013.

- The researcher interested in finding out how the total cost (TC) behaves in relation to the domestic output, in revenue passenger (PAX) and cargo/ freight (FRT), fuel cost (FC) and load factor (LF). The result shall lead us to estimate Sudan Airways cost function, by using Classical Normal Linear Regression Model (CNLRM), and evaluate the model for forecasting. The model represented as follow:

$$
T C_{t}=\beta_{0}+\beta_{1} P A X_{t}+\beta_{2} F R T_{t}+\beta_{3} L F_{t}+\beta_{4} F C_{t}+u_{t} \quad, t=1, \ldots, 10(1)
$$

And satisfied the main features of a good regression model ${ }^{(4),(5),(6),(7)}$, represented by:

Feature (1): Regression line must be fitted to data strongly. Value of R-square should be more than $60 \%$, because the higher R-square value; better the model or model fitted.

Feature (2): Most of explanatory variables (at least 50\%) should individually significant to explain dependent variable. Here t-test was performed.

Feature (3): Explanatory variables should be jointly significant to explain dependent variables. Here F-test should be performed.

Feature (4): Residuals of the model have no serial correlation, no heteroscedasticity and are normally distributed. 
- By using the Simple Exponential Smoothing (smoothing parameter equals 0.7), the researcher forecasted the data of the explanatory variables, and then used the results to forecast Sudan Airways total cost from 2014 to 2018, by using CNLRM.

- CNLRM shall be applied by using the Eview Statistical Package to estimate an airline cost function.

Evaluation of the Model: ${ }^{(8)}$

\section{Results \& Discussion}

The estimated value of total cost by using (CNLRM) is represented as follows:

Table (3): Significant of the Total Cost (TC) Regression Model (2) of Sudan Airways:

\begin{tabular}{|l|l|l|}
\hline Variable & Coefficient & Prob. \\
\hline C & 4848827 & 0.0648 \\
\hline PAX & $-\mathbf{0 . 6 0 8 5 9 6}$ & 0.9465 \\
\hline FRT & 0.008605 & 0.9642 \\
\hline LF & -5131981 & 0.0788 \\
\hline FC & 1.098333 & 0.0001 \\
\hline
\end{tabular}

Source: Prepared by the researcher.

$T C_{t}=4848827-0.608596 \mathrm{PAX}_{\mathrm{t}}+0.008605 \mathrm{FRT}_{\mathrm{t}}-5131981 \mathrm{LF}_{\mathrm{t}}+1.098333 F C_{t}(2)$

As shown in the table (3); there is $25 \%$ of the explanatory variables represented only on fuel cost (FC); are statistically significant at level 5\%; to influence the dependent variable; total cost (TC). According of that, the researcher suspects there is a problem of multicollinearity in the model and expected there is high correlation between any two explanatory variables, which will determined by using the following table:

Table (4): Correlation Matrix of Explanatory Variables:

\begin{tabular}{|l|l|l|l|l|}
\hline $\begin{array}{l}\text { Explanatory } \\
\text { Variables }\end{array}$ & PAX & FRT & FC & LF \\
\hline PAX & 1 & 0.237142 & $\mathbf{- 0 . 5 9 3 8 7 1}$ & $\mathbf{0 . 7 8 7 1 9 8}$ \\
\hline FRT & $\mathbf{0 . 2 3 7 1 4 2}$ & $\mathbf{1}$ & $\mathbf{- 0 . 4 7 6 1 4 8}$ & $\mathbf{0 . 2 5 1 1 7 4}$ \\
\hline FC & $\mathbf{- 0 . 5 9 3 8 7 1}$ & $\mathbf{- 0 . 4 7 6 1 4 8}$ & $\mathbf{1}$ & $\mathbf{- 0 . 7 8 0 3 9 7}$ \\
\hline LF & $\mathbf{0 . 7 8 7 1 9 8}$ & $\mathbf{0 . 2 5 1 1 7 4}$ & $\mathbf{- 0 . 7 8 0 3 9 7}$ & $\mathbf{1}$ \\
\hline
\end{tabular}

Source: Prepared by the researcher.

According this problem, he Chi square P-value of Breusch-Godfrey serial correlation LM test equal 0.0358 is statistically significant at $5 \%$ level, so we can reject the null hypothesis; that residual is serial correlation.As shown in the table (4); there is a higher correlation between the load factor (LF) and passenger (PAX) rather than correlation between the load factor (LF) and freight (FRT), which they are results as not statistical significant in the model (2). So the researcher have to drop one of the two variables (LF and PAX), that registered high correlation $(79 \%)$.

By dropping PAX; which has higher P-value (0.9465); the estimated of total cost regression model is transferred as follow:

$T C_{t}=4861494+0.007127 \mathrm{FRT}_{\mathrm{t}}-5238669 \mathrm{LF}_{\mathrm{t}}+1.09743 F C_{t}(3)$

Table (5): Significant of the Total Cost (TC) Regression Model (3):

\begin{tabular}{|l|l|l|}
\hline Variable & Coefficient & Prob. \\
\hline C & 4861494 & 0.0407 \\
\hline FRT & $\mathbf{0 . 0 0 7 1 2 7}$ & $\mathbf{0 . 9 6 7}$ \\
\hline LF & $\mathbf{- 5 2 3 8 6 6 9}$ & $\mathbf{0 . 0 1 7 8}$ \\
\hline FC & 1.09743 & 00000 \\
\hline
\end{tabular}

Source: Prepared by the researcher.

As shown in the table (5); there is $67 \%$ of the explanatory variables: load factor (LF) and fuel cost (FC); are statistically significant at level $5 \%$; to influence the dependent variable; total cost (TC).

Table (6): Tests Results of Goodness of Fit of the Estimated Regression Model (3):

\begin{tabular}{|l|l|}
\hline R-squared & $\mathbf{0 . 9 9 0 8 4 7}$ \\
\hline Prob (F-statistic) & $\mathbf{0 . 0 0 0 0 0 2}$ \\
\hline Durbin-Watson Stat. & $\mathbf{2 . 3 3 2 2 2 5}$ \\
\hline Jarque-Bera-Normality Prob. & $\mathbf{0 . 6 1 3 0 8 8}$ \\
\hline Breusch-Godfrey Serial Correlation Chi-square Prob. & $\mathbf{0 . 2 3 4 7}$ \\
\hline Breusch-Pagan-Godfrey Heteroscedasticity Chi-square Prob. & $\mathbf{0 . 6 1 1 7}$ \\
\hline
\end{tabular}

Source: Prepared by the researcher. 
The R-squared value of about 0.990847 is statistically a significant value (more than $60 \%$ ), means that about $99 \%$ of variation in the total cost is explained by freight, load factor and fuel cost; that means the goodness of fit of the regression line is very high. Durbin-Watson statistic (2.332225) is found to be 2 , so there is no first-order autocorrelation either positive or negative. Also, the R-squared (0.990847) is less than DurbinWatson statistic, which means that this model is not spurious. The probability of F-statistic equal to 0.000002 is statistically significant at level $5 \%$, means that the explanatory variables: freight, load factor and fuel cost are jointly significant to influence the total cost. The P-value of Jarque-Bera normality test equal to 0.613088 is not statistically significant value at $5 \%$ level; so, we cannot reject the null hypothesis; that residuals are normally distributed.The Chi square P-value of Breusch-Godfrey serial correlation LM test equal to 0.2347 is not statistically significant at 5\% level; so, we cannot reject the null hypothesis; that residuals are not serial correlation.The Chi square P-value of Breusch-Pagan-Godfrey heteroscedasticity test equal to 0.6117 is not statistically significant value at 5\% level; so, we cannot reject the null hypothesis; that residuals are not heteroscedasticity. According to the above results, the researcher concludes that the residuals are normally distributed, not autocorrelated and homoscedastic; so, this result means that the estimated regression model (2) makes sense, and is acceptable to predictive purposes and forecasting.

Forecasting: ${ }^{(8)}$

Table (7): Result of Forecasting Sample 2004-2013 of Sudan Airways:

\begin{tabular}{|l|l|}
\hline Root Mean Squared Error & $\mathbf{6 1 5 9 9 3 . 2}$ \\
\hline Theil Inequality Coefficient & $\mathbf{0 . 0 3 4 0 8 6}$ \\
\hline Bais Proportion & $\mathbf{0 . 0 0 0 0 0}$ \\
\hline
\end{tabular}

Source: Prepared by the researcher.

As shown in table (7), the root mean squared error is equal to 615993.2, while Theil Ineqauality coefficient equal 0.034086 , which is close to zero that means; the predictive power of this model is very strong. Bias proportion equals zero that means, there is no gap between the actual total cost and the predictive total cost, and they are moving closely.

Graph (1): Forecasting Sample 2004-2013:

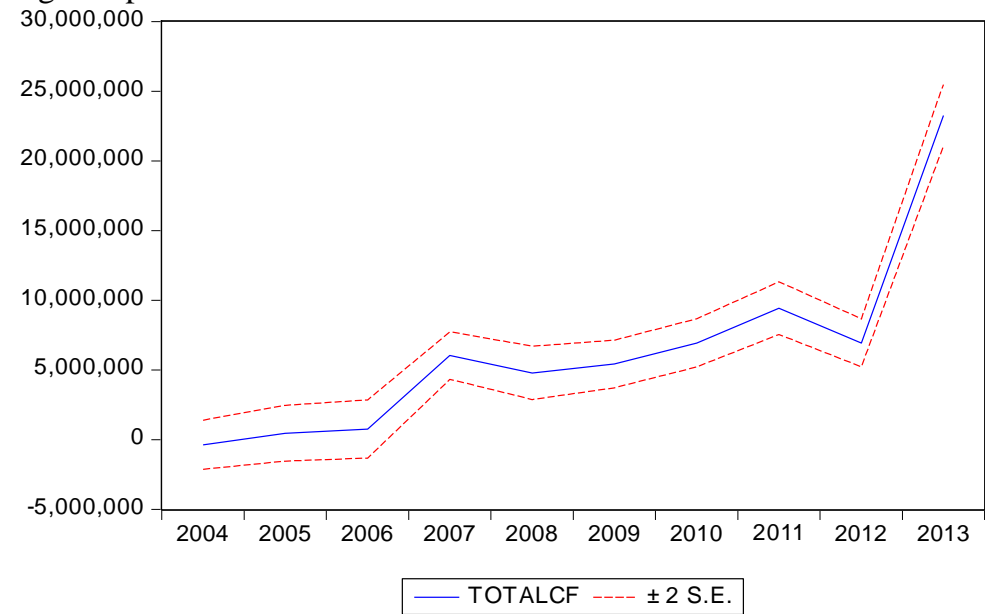

Source: Prepared by the researcher.

As shown in graph (1), the total cost value has been forecast and is passing throw $50 \%$ confidence interval; so, the forecasting of the total cost is significant and the ability of forecasting model is satisfactory.

\section{Forecasting of Sudan Airways Total Cost:}

By using the Simple Exponential Smoothing (smoothing parameter equals 0.7), the researcher forecasted the data of the explanatory variables, and then used the results to forecast Sudan Airways total cost from 2014 to 2018, by using CNLRM which is represented in the following table:

Table (8): Forecasting of Sudan airways Total Cost (US \$) From 2014-2018:

\begin{tabular}{|l|l|l|l|l|l|}
\hline Year & $\mathbf{2 0 1 4}$ & $\mathbf{2 0 1 5}$ & $\mathbf{2 0 1 6}$ & $\mathbf{2 0 1 7}$ & $\mathbf{2 0 1 8}$ \\
\hline Total Cost & $\mathbf{1 8 4 9 6 9 9 3 . 6 6}$ & $\mathbf{8 9 5 2 1 4 3 . 9 0}$ & $\mathbf{6 0 8 8 6 8 8 . 9 7}$ & $\mathbf{5 2 2 9 6 5 2 . 4 9}$ & $\mathbf{4 9 7 1 9 4 1 . 5 5}$ \\
\hline
\end{tabular}

Source: Prepared by the researcher. 
The forecast table above (8), shows that the total cost of Sudan Airways, shall gradually decrease during the next five years. This is clearly noted in Sudan Airways activities as reflected in their current actual status in 2016, due to the decreasing number of their fleet that minimizes their activities.

To recapitulate, the following conclusions are detailed here below:

- The Classical Normal Linear Regression Model (CNLRM) is acceptable to the predictive purpose of forecasting the function of Sudan Airways total cost, with a high statistically significant value of R-squared (99\%), and statistically significant value of F-statistic at level 5\%. Additionally, the residuals were Normally distributed; P-value of Jarque-Bera Normality Test is not statistically significant value at 5\% level, and also the residuals were not autocorrelation (not serial correlation); P-value of Breusch-Godfrey Serial Correlation; LM Test is not statistically significant value at $5 \%$ level, also the residuals were homoscedastic; R-squared P-value of Breusch-Pagan-Godfrey Heteroscedasticity Test; is not statistically significant value at $5 \%$ level. The Theil Ineqauality coefficients values are close to zero and zero Bias Proportions. These results mean that the estimated regression models make sense; with strong power for prediction and forecast.

- From the forecast result for the period 2014-2018 the researcher concluded that the total cost of Sudan Airways, shall gradually decrease during the next five years. This is clearly noted in Sudan Airways activities as reflected in their current actual status in 2016, due to the decreasing number of their fleet that minimizes their activities.

\section{References}

[1]. S.A.C. (2012). Sudan Airways Central Planning Directorate, Khartoum, Sudan.

[2]. S.C.A.A. (2012). Sudan Civil Aviation Integrated Statistics Centre, Khartoum, Sudan.

[3]. Sultan, A.M. (2012). Aviation Prospect in Sudan, Unpublished, Khartoum, Sudan, Issue 3, 1-15.

[4]. Gujarati, D.N. and Porter, D.C. (2009). Basic Econometrics, Fifth Edition, Uni McGraw-Hill Companies.ted State Military Academy,West Point and University of Southern California.

[5]. Maddala, G.S. (1992). Introduction to Econometrics, Second Edition. University of Florida, Macmillan Publishing Company.

[6]. Greene, W.H. (1951). Econometric Analysis, Fifth Edition. New York University, Upper Saddle River, New Jersey.

[7]. Rawlings, J.O., Pantula, S.G. and Dickey D.A. (1932). Applied Regression Analysis: A Research Tool, Second Edition. North Carolina State University, Springer, USA.

[8]. Sultan, M.A., Mudawi, M.H. and Abdellatif, A.H. (2016). Past, Present \& Future of Airlines Domestic Services in Sudan. IOSR Journal of Mathematics (IOSR-JM).12(3), Ver. IV, 74-85. 